\title{
Manuel Andrés Lagos Mieres \\ Paseos Campestres, Veladas y Teatro Alternativas anarquistas para la ocupación del tiempo libre a comienzos del siglo $X X$ (Santiago-Valparaíso. 1890-1930)
}

Santiago, Editorial Indómita, 2015, 211 págs.

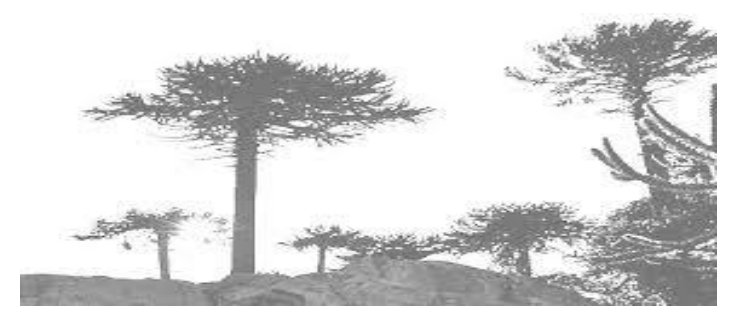

El libro a presentar es innovador en muchos sentidos, pues nos presenta ópticas no clásicas de entender la historia del movimiento obrero, del anarquismo y de sus formas de sociabilización en Chile en un contexto de cambios estructurales, donde se denota un tránsito desde una sociedad tradicional a una más moderna tanto en un sentido económico (no total, pero donde se ven cambios), estatal; y sobre todo en un sentido político y social (cuestión social).

La historia del movimiento anarquista en Chile, así como la historia del movimiento popular en general, y del movimiento obrero en particular, deben su emergencia como aparición en el escenario de los trabajos historiográficos a la innovadora (en su tiempo) Historia Social, la cual puso en evidencia la historia de los grupos oprimidos y el fenómeno de los partidos políticos y el desarrollo de agrupaciones en general, en el mundo del trabajo o experiencias asociados a este y las clases subalternas.

La historiografía en el devenir de la disciplina y los debates surgidos, ha permitido re visitar los procesos históricos que dieron paso al movimiento obrero, la politización de éste y por sobre todo la disputa en el seno de los grupos que buscaron la conducción política del movimiento. Obras como la de Manuel Lagos, nos dan una óptica no clásica de estudiar al proletariado; no como un sujeto que existe sólo en la medida que vende su trabajo a un capitalista, si no que para la ocasión de este libro que se presenta, hace una Historia del tiempo libre, de lo que ocurre fuera de los círculos del mundo del trabajo.

Tiempo libre, paseos campestres, veladas anarquistas, teatro; un gran etcétera de posibilidades para la sociabilización de la población. Pero precisamente dirigida a los que no podían acceder a la industria cultural en Chile, ya sea por su inexistencia o por lo alto del costo de acceso a éstos. En un marco de precarización de las condiciones materiales y subjetivas (la emergencia de la cuestión social) en la sociedad chilena, el anarquismo nos presenta su propia visión de la Regeneración del Pueblo, la cual tiene tanto elementos tradicionales como disruptivos. Pues a diferencia de mutualistas, demócratas e incluso socialistas, el movimiento ácrata presenta formas más radicales de 
concientización en cuanto busca negar el estatus quo del sujeto popular.

La negación de las formas culturales del capital, así como también la negación de lo propiamente popular (como el pensamiento tradicional, la religión, el alcoholismo, la prostitución, la violencia de género) fueron la tónica que los anarquistas buscaron transmitir a la masa humana que buscaban impactar. De esta forma avanzan en la constitución de una cultura ácrata que busca establecerse en la sociedad. En primer lugar, superando la política del liberalismo popular en cuanto ésta sólo planteaba mejoras en el acceso a bienes y servicios, hacia una cultura de confrontación directa entre el capital y el trabajo; pero que no solo se contenta con mejoras del tipo salarial o reformas, sino que también tiene un nutrido paquete de herramientas de sociabilidad y educación proletaria en el tiempo libre.

Como indicamos este no es una veta que solo los anarquistas explotaran, pues era extensa la gama de agrupaciones políticas constituyeron proyectos similares en la forma. Este fenómeno podemos entenderlo en cuanto el anarquismo es parte del árbol del socialismo, y este además es retroactivamente parte de una tradición "popular" más antigua rastreable desde las primeras organizaciones que apelaron al bajo pueblo desde 1850 como la Sociedad de la Igualdad, pasando por diversas formas que tomó la vanguardia que buscaba generar política desde una óptica no tradicional ni de las clases altas, como serán luego Radicales, Demócratas, Laboristas, Mutualistas, etc.

En este sentido el proyecto cultural anarquista formaría no sólo en el mundo del trabajo organizaciones de clase contra la triada Capital/Clero/Estado; sino que en el tiempo libre planteará posibilidades como el teatro, las escuelas racionalistas, estudiantinas, paseos campestres, y por sobre todo una forma de entender el mundo plasmado en acciones concretas asociadas a la moral anarquista.

Es interesante la obra de Manuel Lagos (en específico y también en extenso), pues da cuenta de la sociabilidad y aporta a establecer las redes intelectuales anarquistas, ya que hace el símil y muchas veces explicita las relaciones entre periódicos, grupos de afinidad, sindicatos o agrupaciones de obreros y artesanos, cuerpos filo-dramáticos, etc. Nos presenta de esta forma, las bases del pensamiento anarquista, basado en el pensamiento racional ilustrado, aunque de forma re visitada, pues explícitamente niega la sociedad burguesa y sus formas de explotación tanto activas como pasivas, así como la cosificación de los sujetos, en cuanto se habla de una humanidad nueva más que una clase.

Sin duda alguna es magnánimo el aporte y el avance de la historiografía en cuanto las relaciones sujeto-objeto, pues pasamos de una historia de las clases obreras y sus partidos, a una profundización del relato histórico, descubriendo las negaciones ideológicamente realizadas contra el anarquismo por parte de la Historia Social, donde se presenta a los libertarios como inferiores en la teoría, un estado infantil del movimiento obrero; muy por el contrario, la revisión del periodo nos muestra un extenso desarrollo de redes y acciones en la región. La radicalización y modernización del pensamiento político en la ruptura transicional a la modernidad en Chile hacia finales del siglo XIX y comienzos del XX, podría llegar sin duda alguna, teniendo en cuenta los aportes del autor, a indicarse con bases que fue en gran parte aporte del anarquismo.

En cuanto al libro mismo, indicar que es una publicación, que si bien se asocia a la tesis de Magíster del autor del año 2010 (USACh), está también ligada a la necesidad de buscar los orígenes históricos del movimiento ácrata desde el presente, desde las agrupaciones que reivindican la Idea. El libro tiene una organización que consta de una introducción y dos grandes partes, de las cuales se desprenden 9 y 7 capítulos, respectivamente.

En la introducción principalmente se hace un análisis del periodo, exponiendo sobre actividades culturales propuestas por el anarquismo como alternativas. Durante esta sección se realiza un mapeo de la escena cultural disponible en Santiago-Valparaíso para el periodo; de forma que establece los 
marcos de posibilidades culturales dadas por el Estado y el Mercado, y cuál era el costo asociado a este, develando la capacidad casi nula de los sectores populares a evadir las "mal entretenciones" derivadas de las expresiones culturales populares o religiosas, explicitando el valor de por ejemplo una entrada a un espectáculo, versus el salario diario. De esta forma, nos ayuda a contextualizar el periodo en términos de oferta cultural.

En la primera parte del libro llamada "Una alternativa anarquista para el tiempo libre", expone diversos temas que tratan de explicar el macro de la motivación anarquista por generar una alternativa cultural. Por ejemplo comienza hablando del "modelo positivo" anarquista para la ocupación del tiempo, explicando las diferencias con las otras "alternativas", como las religiosas, burguesas, demócratas, socialistas. Posteriormente se describen las veladas, reuniones al aire libre, dentro o fuera de la ciudad que contenían además de la dispersión misma del acto, momentos serios y expositivos de conferencias anarquistas.

El libro posteriormente nos indica de la inserción de elementos de la cultura popular al anarquismo, tales como el fútbol u otras formas de acción y cultura diversificadas en el movimiento popular, como el carnaval y la estudiantina. Muchas de las negaciones generadas desde el anarquismo a las formas culturales y de sociabilización populares extendidas en la sociedad, se comprenden ya que su postura como anarquistas puede referirse como racional, ilustrada e incluso puritana. De todas formas en las conclusiones de la primera parte del libro el autor matiza esta postura, pues indica que "el modelo "puritano" no fue hegemónico en las prácticas y formas de ocupación del tiempo libre de muchos anarquistas" (129), lo que a su vez se replica a la gran masa que sigue a estos jóvenes en sus ideales. Indicar finalmente a propósito de la primera parte que además se establecen las relaciones de los grupos anarquistas que actuaron en la escena política, así como también sobre las motivaciones del público para asistir a las jornadas ácratas.
En la segunda parte del libro llamada "Representaciones y cuadros artísticos", se hila más fino en cuanto a los grupos artísticos que portaban la Idea ácrata en sus representaciones filo dramáticas, ya que según el autor "ocupaba un lugar central en la presentación de la velada la representación dramática” (135).

En este sentido hace un recorrido por los diversos grupos que componían la escena artística del período asociado al movimiento anarquista, explicando la estructura de las veladas y la configuración de las obras en tanto transmisora de ideas a los espectadores. Luego de individualizar un par de grupos y cuerpos filo dramáticos, el autor nos expone sobre el funcionamiento de estos grupos, hablándonos de su "autonomía y movilidad" (161), ya que si bien éstos estaban asociados a los grupos anarquistas, tenían la capacidad de moverse donde se requiriese su presencia, presentando en muchos casos la misma obra en diversos lugares. Así esta parte del libro es más descriptivo y analiza por ejemplo la propaganda del espectáculo, los espacios que se utilizaban para llevar a cabo las acciones, así como también se transcriben textualmente fragmentos de las obras representadas.

De esta forma, y ya habiendo mostrando en extenso lo expuesto en el libro de Manuel Lagos, podemos visualizar en parte el extenso Proyecto cultural anarquista, el que si bien reivindicó la violencia de masas y las acciones directas a modo violento; se presentó en diversas formas, principalmente de sociabilización de la gran masa bajo sus preceptos ilustrados y racionalistas, teniendo la cultura como un estandarte principal de su proyecto de transformación social.

A modo de comenzar a cerrar, volver a indicar los diversos aportes de esta obra, tanto en su calidad de revisión de una corriente política y actividades culturales asociadas a esta; como a nivel historiográfico, en cuanto fija su construcción de objeto de estudio fuera del mundo del trabajo, donde dicho sea de paso, se ha centrado tradicionalmente la historiografía asociada a las expresiones políticas revolucionarias. 
De esta forma, podemos plantear que el aporte de Manuel Lagos y este libro en específico, pueden abrir muchas nuevas vetas en el estudio de los movimientos sociales en Chile, de los grupos políticos, de la construcción de identidades sociales y de estudios culturales e intelectuales más profundos, en cuanto muestra otra cara de una historia ya contada hace mucho tiempo, y desde la cuál se construyeron los procesos políticos en Chile durante el siglo XX. A su vez, nos da la capacidad de interiorizar en la diversidad de espectros políticos existentes en Chile para la fecha estudiada.

Finalmente a modo de crítica, indicar que al lector le podría quedar cierta hambre de profundización en los procesos en cuanto a su cronología, pues el autor al generar un trabajo expositivo salta de fechas y homologa las temporalidades del anarquismo y sus expresiones culturales a las del resto, sin exponer los contextos de producción de estos a nivel profundo. Claramente para la ciencia de la historia esto puede verse como ventaja, pues como indicamos anteriormente abre nuevas vetas en el estudio de este entramado al que le llamamos anarquismo.

Mauricio A. Tapia Segovia Universidad de Santiago de Chile 